\section{Desafios da pandemia de COVID-19: por uma agenda brasileira de pesquisa em saúde global e sustentabilidade}

\author{
Challenges of the COVID-19 pandemic: for a \\ Brazilian research agenda in global health \\ and sustainability
}

\author{
Desafíos de la pandemia de COVID-19: por una \\ agenda brasileña de investigación en salud \\ global y sostenibilidad
}

Deisy de Freitas Lima Ventura 1

Helena Ribeiro 1

Gabriela Marques di Giulio 1

Patrícia Constante Jaime 1

João Nunes 2

Cláudia Maria Bógus 1

José Leopoldo Ferreira Antunes 1

Eliseu Alves Waldman 1

doi: 10.1590/0102-311X00040620
A emergência internacional relacionada à COVID-19, declarada em 30 de janeiro de 2020 pela Organização Mundial da Saúde (OMS) 1, fez com que as atenções da comunidade científica fossem voltadas mais uma vez para o campo da saúde global. Referimo-nos aqui à saúde global como um novo terreno no qual são reconfiguradas antigas disputas ideológicas, geopolíticas e metodológicas que operam na esfera internacional, formando um campo que pode tanto oferecer oportunidades reais para a busca da equidade 2 como encobrir interesses e agendas particulares dos mais diversos teores ${ }^{3}$. A exemplo do que ocorreu durante a emergência internacional relacionada à síndrome congênita do vírus Zika, da qual o Brasil foi o epicentro em 2016 4, a nova declaração de emergência abriu espaço para a produção científica sobre a COVID-19 em periódicos internacionais de grande impacto, que têm priorizado e defendido o acesso aberto às publicações como forma de contribuir com a resposta internacional 5. Do mesmo modo, a pesquisa sobre a COVID-19 passou a ser induzida por agências internacionais e universidades sob os auspícios de grandes financiadores 6. Porém, a história das crises sanitárias ensina que essa prioridade desaparecerá quando a emergência da COVID-19 tiver fim, constituindo uma estratégia global de investimento ciclotímica, de objeto imprevisível a depender da emergência em questão.

O objetivo deste texto é refletir sobre o novo "boom" da produção acadêmica no campo da saúde global, com base em dois elementos de análise que consideramos fundamentais. O primeiro é a importante mudança do papel que o Estado brasileiro tem desempenhado nas relações internacionais, e particularmente nos foros internacionais relacionados à saúde e ao meio ambiente, inclusive com significativa perda de liderança no que se refere à implantação dos Objetivos de Desenvolvimento Sustentável (ODS) da Agenda 2030 7. O segundo é justamente a sustentabilidade como enfoque fundamental de uma agenda de pesquisa no campo da saúde global. No âmbito deste artigo, a expressão sustentabilidade, que reconhecemos como polissêmica e controversa, é usada sob uma perspectiva crítica e interdisciplinar, salientando questões relacionadas à diversidade cultural, à solidariedade com o planeta (e sua biodiversidade), aos valores éticos e de equidade, igualdade de direitos, justiça e autonomia 8 . Em seu sentido elementar, a sustentabilidade remete à busca de um desenvolvimento econômico e social capaz de voltar-se às necessidades do presente sem comprometer a possibilidade das gerações futuras atenderem às suas próprias necessidades ${ }^{9}$. Note-se que a satisfação das atuais necessidades de determinadas regiões do mundo tem originado desequilíbrios que dificultam ou até impossibilitam a
1 Universidade de São Paulo, São Paulo, Brasil. 2 University of York, York, U.K.

\section{Correspondência}

D. F. L. Ventura Universidade de São Paulo. Av. Dr. Arnaldo 715, São Paulo, SP 01246-904, Brasil. deisyflv@gmail.com 
vida em outras regiões. Porém, endossamos que uma matriz interpretativa multidimensional sobre a sustentabilidade tem enorme potencial para pensar os desafios colocados na modernidade tardia, que se propagam em diferentes domínios e escalas. Caracterizados por incertezas, ambiguidades e complexidades 10, esses desafios demandam respostas e intervenções que levem em conta a necessidade de profundas mudanças do sistema socioeconômico nos modos de produção e consumo 11 em diversas áreas, como energia, agricultura, água, transporte, habitação e saúde. Ademais, a continuidade das políticas públicas é imprescindível para viabilizar soluções estruturais e de longo prazo que de fato fomentem a igualdade, a coesão e a justiça social, por meio de politicas intersetoriais integradas, articuladas ou ao menos coordenadas.

No que se refere às emergências internacionais, defendemos uma agenda de pesquisa permanente, levando em conta não apenas a evolução de doenças específicas, mas o impacto das crises sobre a saúde das populações, além da investigação das causas sociais, ambientais, econômicas e políticas das epidemias. Do mesmo modo que na reação à emergência internacional relacionada ao vírus Ebola que ocorreu na África Ocidental entre 2014 e 2015, uma parte importante da produção sobre a COVID-19 tem veiculado discursos de alto teor normativo, que tendem a enfatizar a busca de vacinas e outras tecnologias, assim como a necessidade de construção de sistemas internacionais de vigilância eficazes, aptos a dar uma resposta imediata e pontual com vista à contenção das epidemias. Sem desmerecer a importância desses estudos e ações, a literatura que se debruça sobre a relação entre a saúde global e o Antropoceno destaca com clareza os limites das soluções tecnológicas como forma de responder ao aparecimento de novos patógenos, influenciando também importantes disfunções políticas e institucionais 12 .

Consideramos fundamental fomentar a pesquisa sobre as emergências de forma contínua e sistemática, e não apenas enquanto elas ocupam as manchetes e suscitam pânico. Para além das respostas rápidas às questões emergentes, é necessário apostar em pesquisas interdisciplinares sobre problemas prioritários de saúde pública que não chamam a atenção das lideranças políticas locais ou globais porque são endêmicos, não mudam com rapidez as taxas de morbimortalidade da população e têm reduzido potencial de propagação em direção aos países ricos.

Nesse sentido, para que se conceba uma resposta internacional sustentável às emergências é imprescindível estudar com profundidade as lições provenientes das cinco emergências internacionais de saúde anteriormente declaradas, duas delas ainda em curso: o poliovírus em regiões de conflitos armados desde 2014; e o Ebola na República Democrática do Congo desde 2019, das quais pouco se fala. É preciso, antes de mais nada, explicar por que os holofotes internacionais estão voltados para certas doenças, e não sobre outras. A produção de conhecimento deve exceder a perspectiva puramente tecnológica e biomédica das emergências, levando em conta questões macroestruturais dos processos de saúde/doença e sua determinação social 13. Nesse particular, a contribuição das ciências sociais e humanas não pode ser negligenciada.

No caso da síndrome congênita do vírus Zika, por exemplo, a sustentabilidade aparece como uma importante chave de análise da emergência. Primeiro, porque a detecção e a contenção da doença só foram possíveis graças à existência de um elemento estrutural e permanente, o Sistema Único de Saúde (SUS). Fica evidente que a resposta às emergências só é possível na presença de sistemas de saúde bem estruturados, com capacidade de vigilância e de pesquisa, conduzidos por uma massa crítica de profissionais bem formados e capacitados para ação nestas três vertentes. Segundo, porque as maiores disfunções da resposta brasileira estão relacionadas ao déficit de sustentabilidade das iniciativas de saneamento e de controle do vetor. Somente $52,36 \%$ da população brasileira e $26,7 \%$ da nordestina têm acesso à coleta de esgoto. $\mathrm{O}$ aumento de temperaturas e as más condições de saneamento favorecem a proliferação dos mosquitos vetores. Assim, ações sustentáveis de saneamento trariam resultados mais benéficos do que o controle de vetores por pesticidas, bastante impactantes à saúde humana e animal. Ações em prol dos direitos das crianças atingidas pela síndrome, assim como dos direitos sexuais e reprodutivos das mulheres, são também elementos importantes da pauta de pesquisa. Efeitos restritivos sobre os direitos das pessoas, antes, durante e depois das emergências, merecem igualmente a atenção dos pesquisadores. A COVID-19 já tem suscitado discriminação em razão da origem 14 e restrições injustificáveis à mobilidade internacional de pessoas 15. Desconstruir o caráter pontual da abordagem das emergências requer igualmente o estudo de sua origem ambiental e da 
potencial repercussão da resposta internacional (ou da ausência dela) sobre o meio ambiente, a saúde e o desenvolvimento local.

Nesse sentido, em que pese o grande destaque que algumas delas são capazes de alcançar, as emergências internacionais constituem apenas uma vertente de um campo muito mais amplo. Esse campo deve incluir uma visão crítica sobre a cooperação internacional em saúde; o estudo da carga dupla de má nutrição que envolve tanto a desnutrição como a obesidade e demanda orientação sobre direitos humanos em alimentação e saúde 16; o impacto das mudanças climáticas, com especial ênfase nas relações entre os fenômenos globais e os locais, situadas na interface entre saúde e meio ambiente; a pesquisa sobre políticas externas dos Estados no campo da saúde e as dinâmicas de poder nas organizações internacionais; as inter-relações entre migrações e saúde, dentre outros temas.

As mudanças climáticas representam uma emergência sem precedentes que ameaça o futuro dos direitos humanos, colocando em risco os avanços em relação ao desenvolvimento e à redução da pobreza alcançados nos últimos 50 anos 17, tornando mais assimétricas as diferenças entre os Estados, eis que repercutem sobretudo nos países de baixa e média rendas. Elas também estão presentes no conceito de sindemia global que apresenta as pandemias de obesidade e desnutrição como um grande desafio para os seres humanos, o meio ambiente e o planeta, vinculado a fatores fundamentais comuns nos sistemas agroalimentares, transporte, desenho urbano e uso do solo 18 . Com sistemas agroalimentares cada vez mais globalizados, os mecanismos de regulação de alimentos assumem papel crucial na agenda internacional da segurança alimentar e nutricional que precisa ser reafirmada como um tema de saúde global 19.

Também é de grande importância o domínio das metodologias empregadas no campo da saúde global, ampliando a capacidade dos pesquisadores brasileiros de dialogar com a literatura internacional da área, tanto para questioná-la como para somar-nos às escolas críticas que vêm surgindo mundo afora, especialmente nos países em desenvolvimento. Do ponto de vista da cooperação acadêmica internacional, as iniciativas no âmbito da América do Sul e do chamado Sul Global devem ser priorizadas. Caminhos metodológicos promissores como os estudos sobre a circulação, difusão e transferência global de políticas públicas poderão ser trilhados. A capacitação metodológica para a realização de estudos de caso, assim como o aperfeiçoamento das metodologias de estudos de casos comparados são também de grande interesse.

Por fim, é preciso estudar o papel que o Brasil desempenhou nas últimas décadas como líder de uma visão crítica da governança global da saúde, com uma política externa neste campo qualificada pelos princípios e pela experiência do SUS 20. A guinada ora promovida pela ascensão das extremas direitas ao Governo Federal implica o esvaziamento do protagonismo histórico do Brasil em temas da maior importância (HIV/aids, propriedade intelectual, acesso a medicamentos essenciais, cooperação Sul-Sul, integração regional etc.) e o deslocamento da atuação brasileira em prol da agenda do setor mais conservador do Partido Republicano norte-americano. A nova correlação de forças no Executivo Federal, resistente à abordagem da questão climática, e o apoio político às práticas agrícolas predatórias também devem agravar esse cenário, tornando ainda mais importantes os estudos críticos sobre o futuro da implantação da Agenda 2030. Nesse sentido, o Brasil passa a integrar uma aliança internacional com potencial particularmente nocivo à saúde das populações menos favorecidas do mundo e ao meio ambiente.

Em um cenário de desprestígio da educação e da ciência, é ainda mais importante que os pesquisadores do campo da saúde global estejam atentos às temáticas nas quais a nova atuação internacional do Brasil repercute de forma mais intensa, a exemplo das questões relacionadas à democracia e aos direitos humanos, e neles particularmente as questões de gênero. Desafiando o predomínio do Hemisfério Norte sobre a agenda de pesquisa da saúde global, e incorporando a sustentabilidade como referência capaz de pautar uma visão crítica dos ciclos de interesse dedicados ao campo, os pesquisadores brasileiros poderão a um só tempo fazer frente à importação automática de uma produção normativa afeita aos interesses do mundo desenvolvido, e contribuir para a consolidação dos enfoques da saúde global nos quais as pessoas e o meio ambiente de fato estão em primeiro lugar 2. 


\section{Colaboradores}

Todos os autores contribuíram com a concepção, elaboração, redação e aprovação do artigo.

\section{Informações adicionais}

ORCID: Deisy de Freitas Lima Ventura (0000-00018237-2470); Helena Ribeiro (0000-0002-13217060); Gabriela Marques di Giulio (0000-00031396-9788); Patrícia Constante Jaime (0000-00032291-8536); João Nunes (0000-0002-0118-0993); Cláudia Maria Bógus (0000-0003-0925-2741); José Leopoldo Ferreira Antunes (0000-0003-39729723); Eliseu Alves Waldman (0000-0001-78076898).

\section{Referências}

1. World Health Organization. Director-General's statement on IHR Emergency Committee on Novel Coronavirus (2019-nCoV), Genebra, 2020. https://www.who.int/dg/speeches/ detail/who-director-general-s-statement-onihr-emergency-committee-on-novel-coronavi rus-(2019-ncov) (acessado em 28/Fev/2020).

2. Biehl J, Petryna A. Peopling global health. Saúde Soc 2014; 23:376-89.

3. Taylor S. 'Global health': meaning what? BMJ Glob Health 2018; 3:e000843.

4. World Health Organization. Statement on the first meeting of the International Health Regulations (2005) (IHR 2005) Emergency Committee on Zika virus and observed increase in neurological disorders and neonatal malformations. https://www.who.int/en/news-room/ detail/01-02-2016-who-statement-on-thefirst-meeting-of-the-international-healthregulations-(2005)-(ihr-2005)-emergencycommittee-on-zika-virus-and-observed-in crease-in-neurological-disorders-and-neona tal-malformations (acessado em 28/Fev/2020).

5. Carr D. Sharing research data and findings relevant to the novel coronavirus (COVID-19) outbreak. Wellcome Trust Statement. https:// wellcome.ac.uk/press-release/sharing-re search-data-and-findings-relevant-novel-coro navirus-COVID-19-outbreak (acessado em 28/ Fev/2020).

6. Global Research Collaboration for Infectious Disease Preparedness. GloPID-R facing the COVID-19 emergency with its members and partners. https://www.glopid-r.org/glopidr-facing-the-COVID-2019-emergency-withits-members-and-partners/ (acessado em 06/ Fev/2020).

7. Organizações das Nações Unidas. Transformando nosso mundo: a Agenda 2030 para o Desenvolvimento Sustentável, 2015. http:// www.itamaraty.gov.br/images/ed_desenvsust/ Agenda2030-completo-site.pdf (acessado em 28/Fev/2020).

8. Silva Junior RD, Ferreira LC, Lewinsohn TM. Entre hibridismos e polissemias: para uma análise sociológica das sustentabilidades. Ambiente e Sociedade 2015; 18:4.

9. World Commission on Environment and Development. Our common future. Oxford: Oxford University Press; 1987.

10. Renn O. Risk governance: coping with uncertainty in a complex world. London: Routledge; 2008.

11. Loorbach D, Frantzeskaki N, Avelino F. Sustainability transitions research: transforming science and practice for societal change. Annu Rev Environ Resour 2017; 42:599-626.

12. Hirschfeld K. Microbial insurgency: theorizing global health in the Anthropocene. Anthropocene Review 2020; 7:3-18.

13. Nunes J, Pimenta DN. A epidemia de Zika e os limites da saúde global. Lua Nova 2016; 98:2146. 
14. Shimizu K. 2019-nCoV, fake news, and racism. Lancet 2020; 395:685-6.

15. Habibi R, Burci GL, Campos TC, Chirwa D, Cinà $\mathrm{M}$, Dagron $\mathrm{S}$, et al. Do not violate the International Health Regulations during the COVID-19 outbreak. Lancet 2020; 395:664-6.

16. Buse K, Patterson D, Magnusson R, Toebes B. Urgent call for human rights guidance on diets and food systems. The BMJ Opinion 2019; 30 oct. https://blogs.bmj.com/bmj/2019/10/30/ urgent-call-for-human-rights-guidance-ondiets-and-food-systems/.

17. Human Rights Council. Climate change and poverty. Report of the special rapporteur on extreme poverty and human rights. https://re liefweb.int/report/world/climate-change-andpoverty-report-special-rapporteur-extremepoverty-and-human-rights (acessado em 28/ $\mathrm{Fev} / 2020$ ).
18. Instituto Brasileiro de Defesa do Consumidor. Sindemia global: obesidade, desnutrição e mudanças climáticas: relatório da Comissão The Lancet. https://alimentandopoliticas.org.br/ wp-content/uploads/2019/08/idec-the_lan cet-sumario_executivo-baixa.pdf (acessado em 28/Fev/2020).

19. Ribeiro H, Jaime PC, Ventura DFL. Alimentação e sustentabilidade. Estud Av 2017; 31:18598.

20. Buss PM. Cooperação internacional em saúde do Brasil na era do SUS. Ciênc Saúde Colet 2018; 23:1881-90. 